Article

\title{
Pre-Polarized Hydrophobic Conducting Polymer Solid-Contact Ion-Selective Electrodes with Improved Potential Reproducibility
}

Ning He, Soma Papp, Tom Lindfors, Lajos Höfler, Rose-Marie Latonen, and Róbert Ervin Gyurcsányi

Anal. Chem., Just Accepted Manuscript • DOI: 10.1021/acs.analchem.6b04885 • Publication Date (Web): 25 Jan 2017

Downloaded from http://pubs.acs.org on January 27, 2017

\section{Just Accepted}

"Just Accepted" manuscripts have been peer-reviewed and accepted for publication. They are posted online prior to technical editing, formatting for publication and author proofing. The American Chemical Society provides "Just Accepted" as a free service to the research community to expedite the dissemination of scientific material as soon as possible after acceptance. "Just Accepted" manuscripts appear in full in PDF format accompanied by an HTML abstract. "Just Accepted" manuscripts have been fully peer reviewed, but should not be considered the official version of record. They are accessible to all readers and citable by the Digital Object Identifier (DOI®). "Just Accepted" is an optional service offered to authors. Therefore, the "Just Accepted" Web site may not include all articles that will be published in the journal. After a manuscript is technically edited and formatted, it will be removed from the "Just Accepted" Web site and published as an ASAP article. Note that technical editing may introduce minor changes to the manuscript text and/or graphics which could affect content, and all legal disclaimers and ethical guidelines that apply to the journal pertain. ACS cannot be held responsible for errors or consequences arising from the use of information contained in these "Just Accepted" manuscripts. 


\title{
Pre-Polarized Hydrophobic Conducting Polymer Solid-Contact Ion- Selective Electrodes with Improved Potential Reproducibility
}

\author{
Ning He ${ }^{a}$, Soma Papp ${ }^{b}$, Tom Lindfors ${ }^{*}{ }^{a}$, Lajos Höfler ${ }^{b}$, Rose-Marie Latonen ${ }^{a}$ and \\ Róbert E. Gyurcsányi*c
}

a Åbo Akademi University, Johan Gadolin Process Chemistry Centre, Faculty of Science and Engineering, Laboratory of Analytical Chemistry, Biskopsgatan 8, FIN-20500 Turku/Åbo, Finland

${ }^{\mathrm{b}}$ Department of Inorganic and Analytical Chemistry, Budapest University of Technology and Economics, Szt. Gellért tér 4, H-1111 Budapest, Hungary

c MTA-BME "Lendület" Chemical Nanosensors Research Group, Department of Inorganic and Analytical Chemistry, Budapest University of Technology and Economics, Szt. Gellért tér 4, 1111, Budapest, Hungary

*Corresponding authors: tom.lindfors@abo.fi and robertgy@mail.bme.hu

\begin{abstract}
Electrically conducting polymers (ECPs) are one of the most popular types of materials to interface ion-selective membranes (ISMs) with electron conducting substrates to construct solid contact ion-selective electrodes (SCISEs). For optimal ion-to-electron transduction and potential stability, the p-doped ECPs with low oxidation potentials such as PPy need to be generally in their conducting form along with providing a sufficiently hydrophobic interface to counteract the aqueous layer formation. The first criterion requires that the ECPs are in their oxidized state, but the high charge density of this state is detrimental for the prevention of the aqueous layer formation. We offer here a solution to this paradox by implementing a highly hydrophobic perfluorinated anion (perfluorooctane sulfonate, PFOS') as doping ion by
\end{abstract}


which the oxidized form of the ECP becomes hydrophobic. The proof of concept is shown by using polypyrrole (PPy) films doped with $\mathrm{PFOS}^{-}$(PPy-PFOS) as the solid contact in $\mathrm{K}^{+}$selective SCISEs ( $\mathrm{K}^{+}$-SCISE). Prior to applying the plasticized poly(vinyl chloride) ISM, the oxidation state of the electrodeposited PPy-PFOS was adjusted by polarization to the known open circuit potential of the solid contact in $0.1 \mathrm{M} \mathrm{KCl}$. We show that the pre-polarization results in a hydrophobic PPy-PFOS film with a water contact angle of $97 \pm 5^{\circ}$, which effectively prevents the aqueous layer formation under the ISM. Under optimal conditions the $\mathrm{K}^{+}$-SCISEs had a very low standard deviation of $E^{0}$ of only $501.0 \pm 0.7 \mathrm{mV}$ that is the best $E^{0}$ reproducibility reported for ECP-based SCISEs.

Keywords: electrically conducting polymer, perfluorinated dopant anion, solid contact ionselective electrode, potassium ion, pre-polarization

\section{Introduction section}

Ion-selective electrodes (ISEs) are established analytical tools in volumetric, clinical and environmental analysis and process control. ${ }^{1-4}$ However, the cost-effectiveness, ease of use, and monitoring capabilities of ISEs, as well as their excellent accuracy demonstrated in the clinical analysis of blood electrolytes would make them suitable for an even wider range of applications. The use of ISEs in potentiometric bioassays, ${ }^{5-9}$ portable paper based platforms ${ }^{10-}$ 12 as well as wearable sensors ${ }^{13,14}$ are relevant examples of emerging applications. However, the single-use disposable ISEs generally required by these applications would benefit from a rugged and cost-effective miniaturized electrode design that is compatible with mass production technologies. ${ }^{15-17}$ In this respect, the replacement of the liquid inner filling solution of conventional ISEs with a solid contact (SC) layer that interfaces the electron conducting 
substrate and the ion selective membrane (ISM) emerges as a major enabling technology. ${ }^{18-21}$ The role of the SC is to provide a stable inner phase boundary potential ${ }^{20,22,23}$ at the substrate/SC and SC/ISM interfaces, and to prevent the aqueous layer formation at the inner interface, which coupled to diffusion of ionic species within the ISM may lead to potential instability. $^{24}$ As all ISMs exhibit water uptake ${ }^{25-31}$, the prevention of the aqueous layer formation $^{32,33}$ with ill-defined ion activity has proven to be a major challenge.

The mainstream of the SCISE research is based on electrically conducting polymers (ECPs) ${ }^{34-}$ ${ }^{36}$, large surface area carbon materials ${ }^{32,37-40}$ and their (nano)composites ${ }^{41-43}$, but also many other important types of SC materials have been reported such as redox polymers ${ }^{44}$, electronion exchange resins ${ }^{45}$, redox-active self-assembled monolayers ${ }^{32}$, tetrakis(4chlorophenyl)borate anion doped nanocluster films ${ }^{46}$, nanoporous $\mathrm{Au}$ films ${ }^{47}$, and threedimensional molybdenum sulfide nanoflowers. ${ }^{48}$ SCISEs with adequate potential stability were reported for both the ECP and carbon materials, but the use of large surface area inert carbon materials apparently results in better potential stabilities and less susceptibility to environmental conditions. $^{37,39}$ In turn, ECPs have an essential advantage in terms of controlled local deposition by electropolymerization aiding the miniaturization and mass fabrication of SCISEs. ${ }^{49-51}$ However, they show a larger degree of complexity both due to the diversity of the ECPs and doping ions as well as due to the mechanism of the stabilization of the inner phase boundary potential. Generally, a mixed ionic and electronic conduction is required for this purpose that is best achieved in the conducting state of the ECP, i.e. in its oxidized form. While this form is usually the most stable it also induces a larger charge density on the polymeric backbone that is compensated during synthesis by incorporation of charge compensating counter ions. The increased charge density, however, commonly 
increases the hydrophilicity of the film making it difficult to prevent the aqueous layer formation even for highly hydrophobic ECPs, raising also adhesion problems.

Here we have addressed this paradox of ECP-based SCISEs by incorporating a highly hydrophobic anion, perfluorooctane sulfonate $\left(\mathrm{PFOS}^{-}\right)$, as the charge compensating (doping) anion in the polypyrrole (PPy) solid-contact film during its electrochemical synthesis. Unlike the tetraphenyl borate derivatives, the $\mathrm{PFOS}^{-}$has besides its hydrophobicity also excellent chemical stability. Electrowetting studies ${ }^{52}$ previously demonstrated that such PPy-PFOS layers can be made superhydrophobic in their oxidized state due to large amount of PFOS anions incorporated in the polymeric matrix. Thus in contrary to most ECPs, such films are in fact more hydrophobic in the oxidized state than in the reduced state. ${ }^{52}$ To ensure the maximum hydrophobicity and stability of the PPy-PFOS solid-contact, we have pre-polarized the $\mathrm{SC}^{53}$ before covering it with the ISM to adjust the PPy-PFOS film to its stable oxidized and hydrophobic form. By this procedure we expected to improve also the reproducibility of the standard potential $\left(E^{0}\right)$, as the large deviation of $E^{0}$ is a common problem of SCISEs. If unsolved, each electrode needs to be calibrated individually for direct potentiometry that is cumbersome, and constitutes a major limitation for development of single-use disposable SCISEs. Small variations in the initial oxidation state and composition of the ECP layer are factors affecting the potential reproducibility of the ECP-based solid-contacts. It is therefore expected that the adjustment of the oxidized form of the ECP should minimize this problem. Indeed, recently it was shown that the standard potential of ECP-based SCISEs can be adjusted by polarizing or short cutting the respective SCISEs against a reference electrode. ${ }^{54}$ However, the potentials of the SCISE are usually drifting after these treatments and the reproducibility of the standard potential lags much behind the state of the art SCISEs having 
redox buffer $^{55}$ and graphene/carbon black-fluorinated acrylic copolymers ${ }^{42}$ as SC with standard deviations (SD) in the best case as low as $0.7 \mathrm{mV}$ and $0.1 \mathrm{mV}$, respectively.

We report here that the pre-polarization of the $\mathrm{SC}$ is a much more efficient way to ensure the reproducibility of the standard potential and for the PPy-PFOS based $\mathrm{K}^{+}$-selective SCISEs. In the best case, it results in the smallest $\mathrm{SD}$ of $0.7 \mathrm{mV}$ reported up to now for ECP-based SCISEs.

\section{Experimental section}

Chemicals. $\mathrm{FeCl}_{3} \cdot 6 \quad \mathrm{H}_{2} \mathrm{O}$, acetonitrile (ACN, 99.5\%, anhydrous), $\mathrm{KCl}$ and heptadecafluorooctanesulfonic acid tetraethylammonium salt (TEAPFOS, $\mathrm{Et}_{4} \mathrm{~N}^{+} \mathrm{SO}_{3}{ }^{-}$ $\left.\mathrm{CF}_{2}\left(\mathrm{CF}_{2}\right)_{6} \mathrm{CF}_{3}, 98 \%\right)$ were received from Sigma-Aldrich and used without additional purification. Pyrrole was also purchased from Sigma-Aldrich and distilled prior to use. High molecular weight PVC (HMW PVC), bis(2-ethylhexyl) sebacate (DOS), potassium tetrakis[3,5-bis(trifluoromethyl)phenyl]borate (KTFPB), potassium ionophore I (valinomycin), and tetrahydrofuran (THF), all Selectophore grade, were purchased from Fluka and used as received. Deionized water (ELGA, 18.2 M 2 ) was used to prepare the aqueous solutions.

Electrosynthesis and pre-polarization of the PPy solid contact. Pyrrole was polymerized with a combined electrochemical and chemical polymerization method from an ACN solution containing $0.1 \mathrm{M}$ pyrrole, $0.05 \mathrm{M}$ TEAPFOS and $2.0 \times 10^{-4} \mathrm{M} \mathrm{FeCl}_{3} \cdot 6 \mathrm{H}_{2} \mathrm{O} .{ }^{52,56}$ Prior to the polymerization, the glassy carbon (GC) electrodes were first polished with $0.05 \mu \mathrm{m} \mathrm{Al}_{2} \mathrm{O}_{3}$ suspension, then on a clean polishing cloth and finally rinsed with deionized water and ACN. In the three-electrode cell, the GC electrodes (incorporated in PEEK bodies), the coiled Pt 
wire and the $\mathrm{Ag} / \mathrm{AgCl}$ wire served as the working, counter and reference electrodes (calibrated vs. ferrocene/ferrocenium), respectively. All freshly prepared solutions (V=3 ml) used for the synthesis and pre-polarization of the PPy films were purged with nitrogen gas for 5 min before the experiments. The chemical polymerization of pyrrole was first initiated for ca. 15 min by adding $\mathrm{FeCl}_{3} \cdot 6 \mathrm{H}_{2} \mathrm{O}$ to the pyrrole-TEAPFOS-ACN solution that was expected to facilitate the electropolymerization and promote the formation of a rougher and more hydrophobic PPy film surface. ${ }^{52}$ The electropolymerization was then carried out galvanostatically for $15 \mathrm{~min}$ at $0.25 \mathrm{~mA} \mathrm{~cm}^{-2}$ (controlled by the Autolab PGSTAT 12 or PGSTAT 30 potentiostats) in a three-electrode one-compartment cell on GC electrodes (d=1.6 $\mathrm{mm})$. After the polymerization, the formed PPy films were characterized by cyclic voltammetry $(\mathrm{CV})$ in monomer- and chloride-free $0.05 \mathrm{M}$ TEAPFOS-ACN electrolyte solution in the three-electrode cell described above and then pre-polarized at $0.18 \mathrm{~V}$ in this solution for 10 min before rinsing the films with ACN. Finally, the PPy films were dried in ambient air for 5 min prior to the ISM casting.

Fabrication of the $\mathbf{K}^{+}$-SCISEs. The ISM cocktail solutions were prepared by adding totally $100 \mathrm{mg}$ of the following membrane components into $1 \mathrm{ml} \mathrm{THF}: 32.9 \%(\mathrm{w} / \mathrm{w}) \mathrm{HMW}$ PVC, 65.7\% DOS, $1.0 \%$ valinomycin, and $0.4 \%$ KTFPB. After the polymerization, prepolarization and drying of the PPy films, $40 \mu 1$ of the ISM cocktail solution was deposited onto the PPy films in three aliquots of $15 \mu 1,15 \mu 1$ and $10 \mu 1$ covering the whole electrode surface and resulting in the ISM thickness of ca. $150 \mu \mathrm{m}$. The three-step drop casting procedure prevented the pinhole formation in the ISM. ${ }^{51}$ The $\mathrm{K}^{+}$-SCISEs were allowed to dry overnight in ambient atmosphere prior to use. 
Characterization of the water contact angle and morphology of the solid contact. The water contact angles (WCAs) were measured with a CAM200 goniometer (KSV Instruments Ltd., Helsinki, Finland) and the static CA was determined after $10 \mathrm{~s}$ of applying the water droplet $(2 \mu \mathrm{L})$ on the PPy film surface. The surface morphology and the thickness of the PPy films were analyzed with scanning electron microscopy (SEM; LEO 1530 Gemini FEGSEM instrument). The PPy films for the WCA and SEM measurements were prepared on Pt sputtered ITO glass.

Water uptake of the PPy-PFOS solid contact. The water uptake of the PPy-PFOS film deposited on a Pt sputtered ZnSe reflection element was determined with Fourier transform infrared attenuated total reflectance (FTIR-ATR) technique using the previously reported experimental setup. ${ }^{29,31,57}$ The electropolymerization of the PPy-PFOS film on $\mathrm{ZnSe}$ is described in the Supporting Information. Briefly, the sample compartment of the FTIR instrument was purged with dry air for 30 min before starting the water uptake measurements of the PPy-PFOS film. The background spectrum and the first FTIR spectrum in the measurement sequence were recorded without any electrolyte in the cell. After measuring the first spectrum (a straight line) the cell was quickly filled with deionized water and the FTIR spectra were then measured once every minute for the first $2 \mathrm{~h}$ and with 15 min intervals during the next $22 \mathrm{~h}$. The FTIR measurements were done with a Bruker IFS 66/S spectrometer equipped with a DTGS detector. Twenty-five interferograms were recorded for each spectrum measured with the resolution of $4 \mathrm{~cm}^{-1}$ and the gain factor of 64 . The penetration depth $\left(d_{p}\right)$ of the evanescent wave was estimated with the Harrick equation ${ }^{58}$ to be ca. $0.5-0.6 \mu \mathrm{m}$ and ca. $1.1-1.3 \mu \mathrm{m}$ in the wavenumber regions of $3000-3700 \mathrm{~cm}^{-1}(\mathrm{OH}$ stretching vibrations of water $)^{59,60}$ and $1500-1800 \mathrm{~cm}^{-1}$ (H-O-H bending vibrations $)^{61}$, 
respectively, by assuming that the $\mathrm{n}_{\mathrm{ZnSe}}=2.430-2.435$ and $\mathrm{n}_{\mathrm{PPy}}=1.5 .{ }^{62}$ However, the penetration depths can be influence to some extent by the $30 \mathrm{~nm}$ thick sputtered Pt layer that covers the ZnSe surface. The mathematical modelling of the water diffusion coefficients from the water uptake spectra is described in the Supporting Information.

In situ FTIR-ATR spectra of the PPy-PFOS film prepared on the Pt sputtered ZnSe were also recorded at different applied potentials in the spectroelectrochemical cell in the presence of 0.05 M TEAPFOS-ACN as the electrolyte solution. This was made in order to characterize the oxidation and reduction behavior of the film. The in situ FTIR-ATR spectra were recorded during a slow voltammetric scan $\left(2 \mathrm{mV} \mathrm{s}^{-1}\right)$ between -0.8 and $0.52 \mathrm{~V}$ with $0.12 \mathrm{~V}$ potential intervals. Twenty-five interferograms were recorded for each spectrum with $4 \mathrm{~cm}^{-1}$ spectral resolution. The measured spectra were compared to a reference spectrum recorded at $-0.8 \mathrm{~V}$ which was recorded after pretreatment for $30 \mathrm{~s}$ at this potential. The spectra shown later in Figure 2 therefore describe the spectral differences from the reference state.

Potentiometric measurements. Potentiometric measurements carried out in this work including the determination of the selectivity coefficients, $\mathrm{O}_{2}, \mathrm{CO}_{2}$ and light sensitivity of the $\mathrm{K}^{+}$-SCISEs were made using a 16-channel high input impedance voltmeter (Lawson Labs, Inc. Malvern, PA). All other details are provided in the Supporting Information.

\section{Results and discussion}

Characterization of the PPy-PFOS solid contact. The CVs of three identical PPy-PFOS solid contacts measured in 0.05 M TEAPFOS-ACN solution are shown in Figure 1 revealing that the oxidation of the PPy film to its electrically conducting form occur at $E>$ ca. $-0.6 \mathrm{~V}$ in 
a reproducible manner. The low oxidation potential is typical for PPy prepared with a bulky immobile anion such as dodecylsulphate ${ }^{63}$ and makes the PPy-PFOS film electrically conducting already at relatively low negative potentials. Potentiometric measurements of the bare PPy-PFOS film in the presence of TEAPFOS showed a sub-Nernstian cationic slope of 25.6 $\pm 3.8 \mathrm{mV} /$ decade $(n=4)$ at concentrations between $10^{-3} \mathrm{M}$ to $10^{-2} \mathrm{M}$ (data not shown) suggesting that the film is dominantly exchanging cations $\left(\mathrm{TEA}^{+}\right)$when it is cycled in the TEAPFOS-ACN electrolyte solution (Figure 1). No potentiometric response was observed in $10^{-3}-10^{-1} \mathrm{M} \mathrm{KCl}$ as the electrolyte solution.

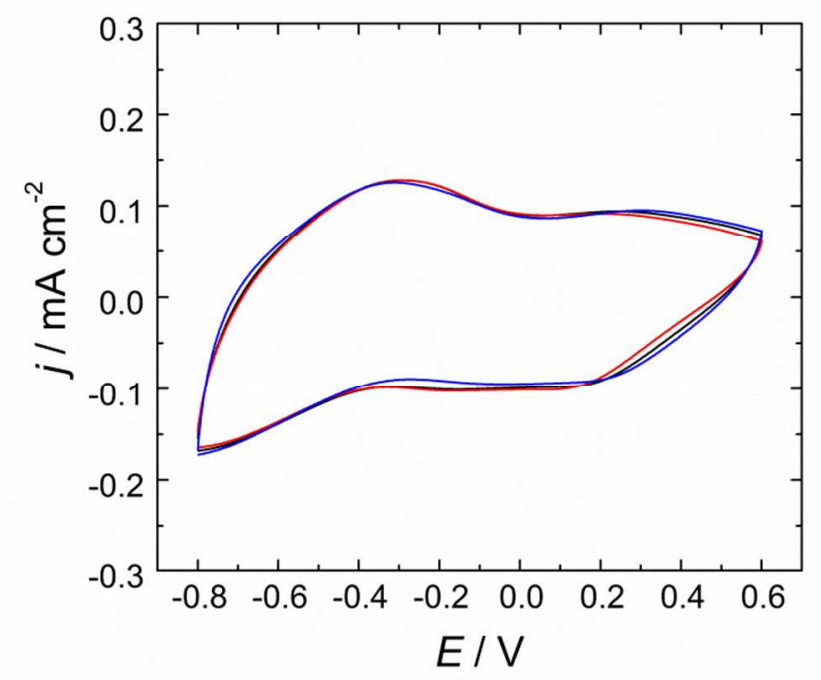

Figure 1. CVs of three identically prepared PPy-PFOS solid contacts recorded in $0.05 \mathrm{M}$ TEAPFOS-ACN solution.

The in situ FTIR-ATR measurements carried out on the PPy-PFOS films electropolymerized on Pt sputtered ZnSe confirmed that the transition from the reduced form to the electrically conducting oxidized form occurs between ca. $-0.55 \mathrm{~V}$ to $-0.2 \mathrm{~V}$ (Figure 2). In this potential range, the infrared active vibrational (IRAV) bands of PPy, which are characteristic for the conducting form of PPy-PFOS, grow in intensity with the main bands located at 852, 897, 
1053, 1167, 1344, 1460 and $1572 \mathrm{~cm}^{-1}$. The wavenumbers are taken from the spectra measured at $0.16 \mathrm{~V}$. The bands at 852 and $897 \mathrm{~cm}^{-1}$ are assigned to $\mathrm{C}-\mathrm{H}$ out-of-plane bending and the band at 1053 and $1344 \mathrm{~cm}^{-1}$ to $\mathrm{C}-\mathrm{H}$ in-plane bending. ${ }^{64}$ The shift of the band at 1053 $\mathrm{cm}^{-1}$ to higher energies upon oxidation may be explained by the higher energy required to bend the longer bonds in the quinoid form of PPy-PFOS. The band at $1167 \mathrm{~cm}^{-1}$ is assigned to pyrrole ring breathing vibrations which are symmetrical expansion and contraction movements without involving changes in bonding angles. ${ }^{64}$ The bands at 1344,1460 and $1572 \mathrm{~cm}^{-1}$ are associated with $\mathrm{C}-\mathrm{N}$ and $\mathrm{C}-\mathrm{C}$ symmetric ring stretching vibrations, although the band at $1572 \mathrm{~cm}^{-1}$ predominantly arises from $\mathrm{C}=\mathrm{C}$ stretching vibrations. ${ }^{64,65}$ On the other hand, the shifts of these bands towards lower energies may be explained by the lower energy required to stretch the longer bonds formed upon oxidation in the quinoid form of PPy. The charging-discharging reaction of ECP films is highly dependent on the nature of the doping ion resulting in some shifts of the IRAV bands of PPy-PFOS compared to PPy doped with other counter ions $\left(\mathrm{LiClO}_{4}, \mathrm{NaClO}_{4}\right.$ and dodecylsulphate). ${ }^{66}$ The broad absorbance above $1700 \mathrm{~cm}^{-1}$ that increases with the applied potential is characteristic for ECPs and assigned to the formation of charge carriers in the polymer matrix and the conversion of PPy-PFOS into the conducting state. ${ }^{67}$ 


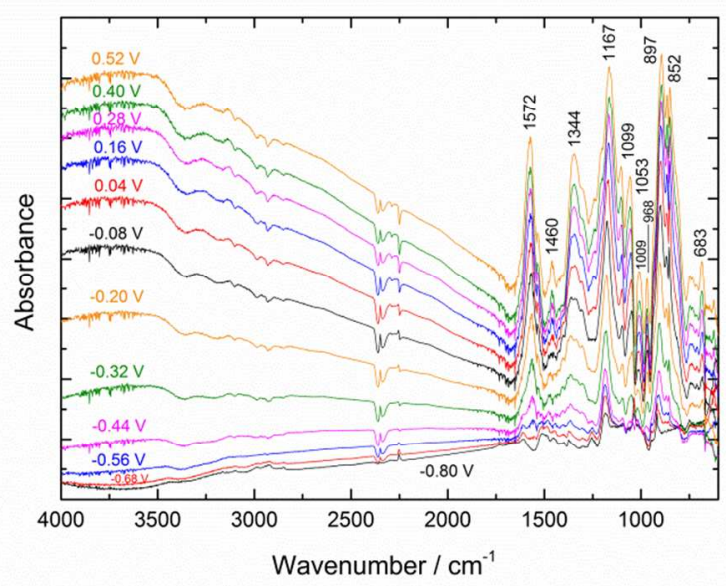

Figure 2. In situ FTIR-ATR spectra of the PPy-PFOS film measured in 0.05 M TEAPFOS$\mathrm{ACN}$ in the potential range of $-0.8 \mathrm{~V}$ to $0.52 \mathrm{~V}$ with $0.12 \mathrm{~V}$ potential intervals. The wavenumbers shown are taken from the spectra measured at $0.16 \mathrm{~V}$.

Figure S-1 is a typical top view obtained by SEM of the PPy-PFOS film revealing that the film has a cauliflower-like and relatively compact morphology with some minor surface roughness. Unlike the SEM image shown in ref. 52 and 56, the mixed chemical and electrochemical polymerization method results in a more compact film rather than a rough and porous PPy film structure. This can be due to the difference in the electrode substrate used in this work (GC) and in ref. $56(\mathrm{Au})$, but also to the rather low $\mathrm{FeCl}_{3} \cdot 6 \mathrm{H}_{2} \mathrm{O}$ concentration of $2 \times 10^{-4} \mathrm{M}$. The PPy-PFOS film in Figure S-1 had a thickness of ca. $1.4 \mu \mathrm{m}$ that was measured from the cross section of the film. The WCA of the PPy-PFOS films polarized for $10 \mathrm{~min}$ at $-0.4 \mathrm{~V}$ and $0.2 \mathrm{~V}$ were $67 \pm 17^{\circ}$ and $97 \pm 5^{\circ}(n=3)$, respectively. This shows that the films are more hydrophobic in their conducting form, contrary to most other ECPs, and that the higher pre-polarization potential facilitates the incorporation of larger amounts of PFOS anions into the PPy matrix. 
Pre-polarization of PPy solid contacts. A major advantage of ECP-based SCs as compared with those featuring solely capacitive stabilization is that the $E^{0}$ values of the respective SCISEs can be adjusted by an applied external potential. However, this potential adjustment is of practical use only if a stable state of the $\mathrm{SC}$ is reached by the applied potential to guarantee long-term potential stability. Otherwise, the SCISEs will slowly drift to an equilibrium state. We found that it is better to make the potential adjustment of the SCs before the ISMs are applied to not involve mass transport through the ISM. To find out the equilibrium potential, the bare PPy-PFOS solid contacts (without the ISM) were polarized in $0.05 \mathrm{M} \mathrm{TEAPF}_{6}-\mathrm{ACN}$ at $-0.4 \mathrm{~V}$ and $1.0 \mathrm{~V}$, and then placed in direct contact with aqueous 0.1 $\mathrm{M} \mathrm{KCl}$ solution at ambient oxygen conditions. Figure 3 shows relatively large potential drift for the differently pre-polarized PPy films during the first 6-8 h. After $24 \mathrm{~h}$ the potential had stabilized at ca. $0.18 \mathrm{~V}$. To minimize the potential drift of the $\mathrm{K}^{+}$-SCISEs originating from the buried solid-contact, the PPy solid-contact was therefore pre-polarized at $0.18 \mathrm{~V}$ for 10 min to adjust the oxidation state of the ECP to a suitable level for the use of the SCISEs in the $\mathrm{KCl}$ solutions. Given the low oxidation potential of PPy-PFOS, the pre-polarization potential of $0.18 \mathrm{~V}$ is high enough to convert the film to its oxidized conducting form (cp. with the FTIRATR spectra in Figure 2). 


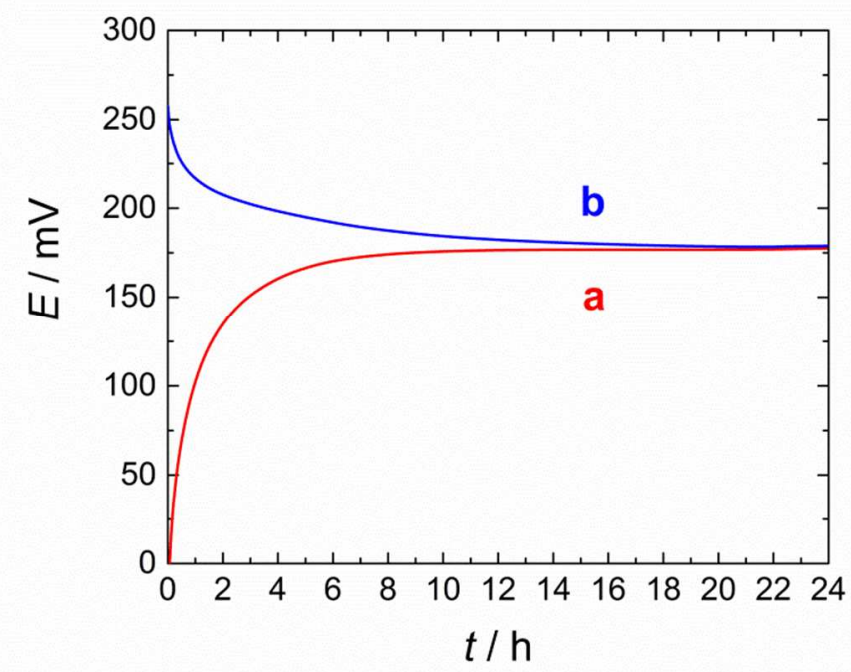

Figure 3. The potential stability of the PPy-PFOS films measured in $0.1 \mathrm{M} \mathrm{KCl}$ for $24 \mathrm{~h}$ after pre-polarization at (a) $-0.4 \mathrm{~V}$ and (b) $1.0 \mathrm{~V}$.

Water uptake of the PPy-PFOS solid contact. The water uptake of plasticized PVC-ISMs has been recently characterized by the FTIR-ATR spectroscopy $y^{29,30,68}$ and the oven based coulometric Karl Fischer titration technique. ${ }^{68}$ It was shown that water diffuses readily through the PVC-ISMs and that the water content of the membrane is influenced by the chemical composition of the electrolyte solution contacting the ISM. It was found that the water content was highest when the ISM was in contact with deionized water while the water content of the ISM decreased in $0.1 \mathrm{M} \mathrm{CaCl}_{2}$ solution. ${ }^{68}$ In deionized water, the diffusion of water in the plasticized PVC-ISM was best described by a model consisting of two diffusion coefficients related to fast (ca. $\left.1.4 \times 10^{-7} \mathrm{~cm}^{2} \mathrm{~s}^{-1}\right)$ and slow $\left(1.2 \times 10^{-8} \mathrm{~cm}^{2} \mathrm{~s}^{-1}\right)$ water transport in the PVC membranes. ${ }^{30}$ Therefore, before applying the ISM on top of the PPy-PFOS solid contact, we have studied the water barrier properties of the bare PPy-PFOS film pre-polarized at $0.18 \mathrm{~V}$ with the FTIR-ATR spectroscopy in the extreme situation when the SC is fully exposed to water without the protecting PVC-ISM top layer. This was done to predict how the 
$\mathrm{SC}$ will behave if it comes in contact with water. However, it should be remembered that as a buried layer beneath the ISM, the PPy-PFOS solid-contact is exposed to only very minor amounts of water (ca. 50-500 ppm), corresponding to the water concentration in plasticized PVC membrane. ${ }^{68}$ The FTIR-ATR spectra measured during the water uptake of the PPyPFOS solid contact is shown in Figure 4. After exposure of the PPy-PFOS film to water at $\mathrm{t}=0$ min, the gradually increasing $\mathrm{OH}$ stretching bands of water at ca. $3000-3700 \mathrm{~cm}^{-1} 29-31,57,69$ reveal that the water uptake of the SC is very slow. The penetration depth of the IR beam is ca. 0.5-0.6 $\mu \mathrm{m}$ in this wavenumber region. Due to the absence of water bands in the very beginning of the FTIR measurement ( $\mathrm{t}=1 \mathrm{~min})$, it is assumed that the evanescent field of the IR beam penetrates only the PPy film (included in the background spectrum) in the wavenumber region of $3000-3700 \mathrm{~cm}^{-1}$. On the other hand, at $1640 \mathrm{~cm}^{-1}$ where the first overtone of the $\mathrm{O}-\mathrm{H}$ stretching vibrations of water has its absorbance maximum, the penetration depth of the evanescent field is ca. twice higher (ca. 1.1-1.3 $\mu \mathrm{m}$ ) and due to the non-uniform film thickness of ca. 265-680 nm (the PPy film is thicker at the film edges), the evanescent field penetrates both the PPy-PFOS film and water already from the very beginning of the water uptake measurements. A strong water band at $1640 \mathrm{~cm}^{-1}$ is therefore observed in the first water uptake spectrum measured at $t=1$ min (not shown). Mathematical simulations $^{29,31}$ based on the integrated absorbance of the OH-stretching bands at 2720-4060 $\mathrm{cm}^{-1}$ (see Supporting Information) showed that the water diffusion in the PPy-PFOS film could be described with a model consisting of two diffusion coefficients: $D_{1}=9 \times 10^{-13} \mathrm{~cm}^{2} \mathrm{~s}^{-1}$ and $\mathrm{D}_{2}=2 \times 10^{-14} \mathrm{~cm}^{2} \mathrm{~s}^{-1}$ (Figure S-2). The diffusion coefficients reveal that the water diffuses slowly through the PPy-PFOS film and that it acts as an efficient water barrier. However, the 
modelled water diffusion coefficients should be considered only as approximate as the modelling was carried out with the mean film thickness of $472 \mathrm{~nm}$.

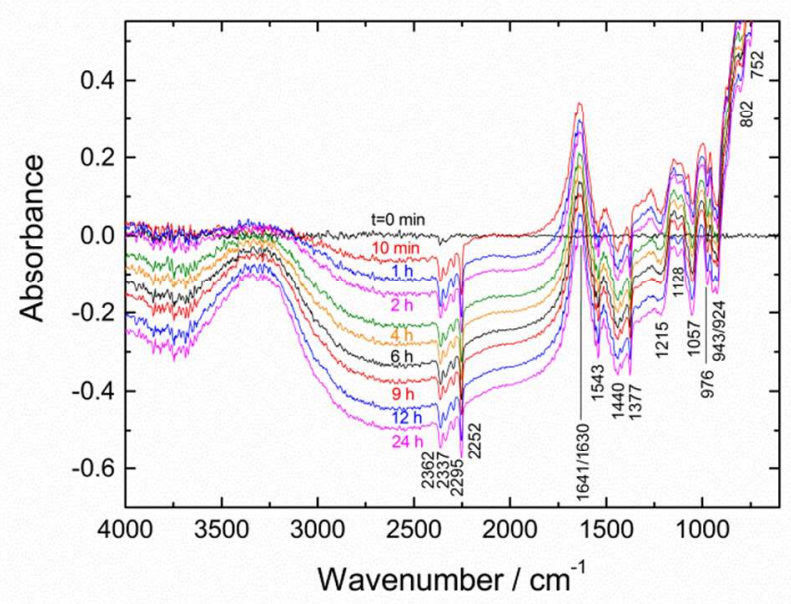

Figure 4. The FTIR-ATR spectra measured during the water uptake of the neat PPy-PFOS solid contact in deionized water during $24 \mathrm{~h}$.

Simultaneously with the increasing water bands in the FTIR-ATR spectra in Figure 4, the spectral drift to negative absorbance values show that the PPy-PFOS film is slightly reduced during the water uptake measurements. The spectra in Figure 4 were measured with a signal amplification of 64 (included in the figure) and the real spectral changes are therefore smaller than what is shown in Figure 4. The decrease of the oxidation state of PPy is especially clearly seen at wavenumbers $>1700 \mathrm{~cm}^{-1}$, which is characteristic for the broad electronic absorbance band of the ECPs. ${ }^{67}$ Also, several downward pointing negative IR bands related to PPy, PFOS $^{-}$and ACN overlap with the increasing water bands in the IRAV region at wavenumbers $<1500 \mathrm{~cm}^{-1}$. The band assignments are given in Table S-1 in the Supporting Information. It should be noted that the bands of the conducting form of PPy, the PFOS ${ }^{-}$anion and traces of ACN are all included in the background spectrum of the PPy-PFOS film and therefore they decrease in intensity as the film is reduced (i.e. its oxidation state is lowered). 
In Figure 4, the negative vibrational band at $1128 \mathrm{~cm}^{-1}$ ascribed to asymmetric $\mathrm{SO}_{3}$ stretching vibration in PFOS $^{-},{ }^{70}$ which increases in intensity with time, indicates that some of the PFOS leaves the film during the water uptake measurements. The concentration gradient of PFOS between the PPy film and deionized water is expected to be the main driving force for some of the PFOS $^{-}$anions to diffuse from the PPy matrix to the solution phase.

When the PPy-PFOS is applied as the SC beneath the PVC-ISM, the oxidation state changes are expected to occur only to a very minor extent compared to the changes in Figure 4 and the PPy film should therefore retain its hydrophobicity under the ISM. However, it can be speculated that slow changes in the oxidation state can possibly occur over longer time periods due to the (low) water solubility of $\mathrm{PFOS}^{-}$if the $\mathrm{SC}$ comes into contact with water diffusing through the ISM.

Initial potential stability and calibration of the $\mathbf{K}^{+}$-SCISEs. The pre-polarization of the SCs to a stable form may be also beneficial in terms of achieving much shorter conditioning times. ${ }^{71}$ It was found that the $\mathrm{K}^{+}$-SCISEs reached a stable potential after $1 \mathrm{~h}$ from their very first contact with unstirred aqueous $0.1 \mathrm{M} \mathrm{KCl}$ solution (not shown). After stabilization of the potential during the first hour, the SCISEs showed a relatively low potential drift of $-71 \mu \mathrm{V} \mathrm{h}^{-}$ ${ }^{1}$ for the next $15 \mathrm{~h}$. The potential traces and calibration graphs of the $\mathrm{K}^{+}$-SCISEs in $10^{-10}-10^{-3}$ $\mathrm{M} \mathrm{KCl}$ solutions are shown in Figure S-3 and Figure 5, respectively. The electrodes gave a linear potentiometric response up to $0.1 \mathrm{M} \mathrm{KCl}$ (not shown) and showed a close to Nernstian slope of $57.0 \pm 0.1 \mathrm{mV} /$ decade $\left(\mathrm{r}^{2}=0.999\right)$. The LOD was $(8.8 \pm 2.1) \times 10^{-8} \mathrm{M}$ if the electrodes were conditioned at low $\mathrm{KCl}$ concentrations $\left(10^{-9} \mathrm{M}\right)$ prior to the calibration and limiting the calibration up to $1 \mathrm{mM} \mathrm{KCl} \mathrm{(Figure} \mathrm{5).} \mathrm{In} \mathrm{Figure} \mathrm{S-3,} \mathrm{the} \mathrm{potentials} \mathrm{were} \mathrm{measured} \mathrm{with}$ 
intervals of one second during $300 \mathrm{~s}$ at each $\mathrm{Ca}^{2+}$ concentration and the potential values shown in Figure 5 were taken in the very end of this 5 min period. The selectivity coefficients $\left(\log K_{\mathrm{K}^{+}, \mathrm{J}}^{\text {pot }}\right)$ of the $\mathrm{K}^{+}$-SCISEs for most relevant interfering ions in biological samples was found to be between -4.5 to -5.6 (except of $\mathrm{J}=\mathrm{NH}_{4}{ }^{+}$) as shown in Table $\mathrm{S}-2 .{ }^{72}$ The optimized $\mathrm{K}^{+}$-SCISEs showed in the best case a very good $E^{0}$ reproducibility of only $501.0 \pm 0.7 \mathrm{mV}$ $(n=4)$ with a SD that is equal to that obtained for the redox buffer based SCISEs $( \pm 0.7 \mathrm{mV})^{55}$ and which surpasses the SDs of the state of the art ECP based SCISEs (usually ca. $\pm 20 \mathrm{mV}$ ). ${ }^{51}$ The improved $E^{0}$ reproducibility of the $\mathrm{K}^{+}$-SCISEs is ascribed to the combination of the prepolarization and hydrophobicity of the PPy-PFOS solid contact counteracting the detrimental aqueous layer/pool formation beneath the ISM. This reproducibility was confirmed in a subsequent batch $(n=3)$. However, we started to see larger deviation in $E^{0}$ within a batch and batch-to-batch when we increased the number of electrodes in an interlaboratory study. Two factors were identified to lead to these larger deviations: (i) there were GC substrate electrodes that even after multiple re-making of the SCISEs showed consistently $E^{0}$ values far from the mean value suggesting that the quality of the substrate electrodes may influence the $E^{0.73}$ (ii) a larger deviation from $E^{0}$ was also obtained for the $\mathrm{K}^{+}$-SCISEs prepared at the two co-operating laboratories (authoring this paper) by using the same protocols, but different instrumentation and batches of chemicals for the SC and ISM preparation. For the best $E^{0}$ reproducibility we removed these electrodes and the $\pm 0.7 \mathrm{mV}$ represents conditions where the above mentioned factors do not influence the $\mathrm{SD}$ of the $E^{0}$. This suggests that the current practice of $E^{0}$ reproducibility determination generally based on a small batch of electrodes may need to be extended to larger batches and that the quality of the substrate electrodes may 
need to be carefully considered. The latter requirement would be probably best addressed by using microfabricated substrate electrodes and clean-room conditions.

After keeping the $\mathrm{K}^{+}$-SCISEs in $10^{-4} \mathrm{M} \mathrm{KCl}$ for 46 days, the electrodes showed a Nernstian slope of $58.1 \pm 0.2 \mathrm{mV} /$ decade $\left(\mathrm{r}^{2}=0.999\right)$, but almost one decade higher LOD of $(6.4 \pm 1.0) \times 10^{-}$

${ }^{7} \mathrm{M}$ than for the freshly prepared SCISEs (not shown). However, no special pre-treatment protocols at low $\mathrm{KCl}$ concentrations were applied to these electrodes before starting the calibration that can partially explain the higher detection limit. Regardless of the higher LOD, the $\mathrm{K}^{+}$-SCISEs showed a very good $E^{0}$ reproducibility of $577.1 \pm 3.1 \mathrm{mV}(n=3)$ still after 46 days, which equals to a relatively low $E^{0}$ drift of $69 \mu \mathrm{V} \mathrm{h}^{-1}$ during this time period. This additionally proves the robustness of the $\mathrm{K}^{+}$-SCISEs. In comparison, the SD of $E^{0}$ for the redox buffer based SCISEs $(n=5)$ had increased from $0.7 \mathrm{mV}(\mathrm{t}=1 \mathrm{~h})$ to $16.3 \mathrm{mV}$ already during the first $24 \mathrm{~h}$ of use. ${ }^{55}$ During this time the SCISEs showed a potential drift of ca. 0.6 $\mathrm{mV} \mathrm{h}^{-1}$

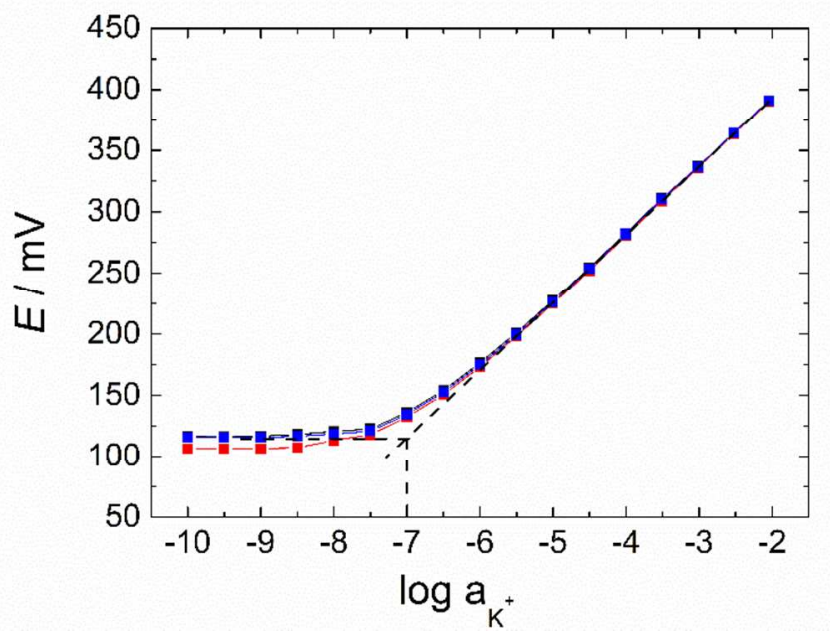


Figure 5. The calibration graphs of PPy-PFOS based $\mathrm{K}^{+}$-SCISEs $(n=3)$. The dashed lines illustrate the determination of the LOD.

Potentiometric aqueous layer test. Due to the water uptake of the plasticized PVC-ISMs, it is possible that a water layer forms beneath the ISM in the SCISE structure. We investigated this possibility with the potentiometric aqueous layer test (Figure 6$).^{32}$ The lack of potential drifts upon changing between solutions with high concentration of primary $\left(\mathrm{K}^{+}\right)$and interfering $\left(\mathrm{Na}^{+}\right)$ions, as shown in Figure 6, revealed no indications of an aqueous layer formation. This indicates that the PPy-PFOS solid contact acts as an efficient water barrier, which is very unusual since it is difficult to avoid aqueous layer formation for SCISEs prepared with PVC-ISMs which have a relatively high water uptake. ${ }^{30}$ This has been achieved only in a few cases, e.g. by using hydrophobic polyazulene ${ }^{74}$ and PPy doped with hexacyanoferrate (II)/(III) ${ }^{51}$ as the SCs in $\mathrm{K}^{+}$-SCISEs. The absence of the aqueous layer formation has been also reported for poly(3-octylthiophene) (POT) based $\mathrm{Ca}^{2+}$-SCISEs by using chemically prepared and almost electrically non-conducting POT as the SC. ${ }^{75}$

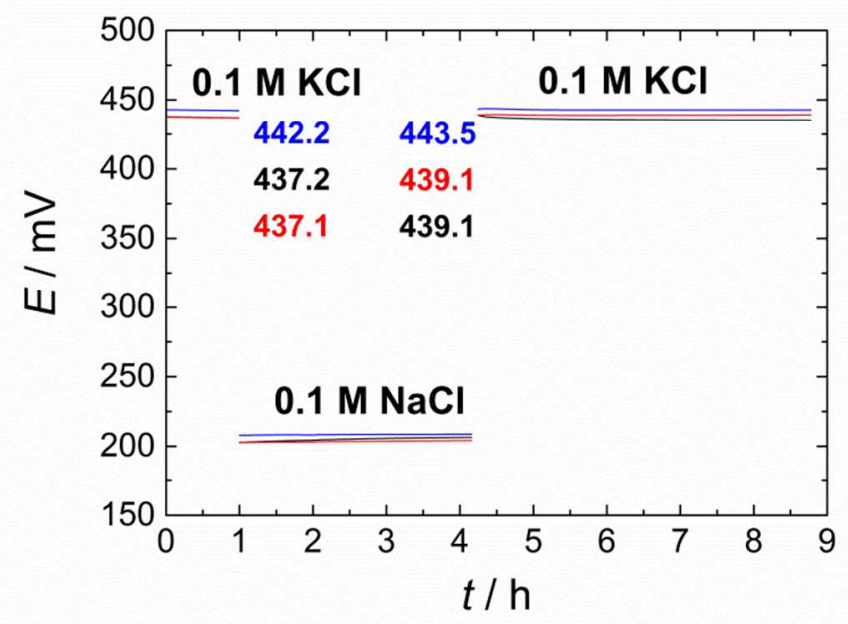

Figure 6. Potentiometric aqueous layer test of PPy-PFOS based $\mathrm{K}^{+}$-SCISEs $(n=3)$. 
The electrode potentials in Figure 6 are practically the same before and after exposure to 0.1 $\mathrm{M} \mathrm{NaCl}$ solution for $4 \mathrm{~h}$ showing the good potential stability of the SCISEs. In Figure 6, the $\mathrm{K}^{+}$-SCISE potentials in $0.1 \mathrm{M} \mathrm{KCl}$ are ca. $57 \mathrm{mV}$ higher than for $10^{-2} \mathrm{M} \mathrm{KCl}$ in Figure 5 (calibration graph) showing that the electrodes had a Nernstian response between $10^{-2} \mathrm{M}$ and $0.1 \mathrm{M} \mathrm{KCl}$. No sulphur could be detected at $2.3 \mathrm{keV}^{76}$ neither on the top (solution side) nor the bottom side (facing the SC) of the PVC-ISM in the energy dispersive X-ray spectra of freshly prepared $\mathrm{K}^{+}$-SCISEs that had not been in contact with water. This indicates that the bulky $\mathrm{PFOS}^{-}$anions stay in the PPy solid contact making it hydrophobic and do not diffuse into the PVC-ISM during the electrode preparation. The absence of the aqueous layer formation in Figure 6 reveals also that the oxidation state of the PPy-PFOS solid contact is unaffected beneath the ISM. It therefore functions as an efficient water barrier in accordance with the low water diffusion coefficients obtained by the mathematical modelling.

Carbon dioxide, oxygen and light sensitivity. The PPy-PFOS based $\mathrm{K}^{+}$-SCISEs showed no light sensitivity and a very minor drift of only $-0.7 \mathrm{mV} \mathrm{h}^{-1}$ when the $0.1 \mathrm{M} \mathrm{KCl}$ solution that was first purged with $\mathrm{N}_{2}$ was saturated with $\mathrm{CO}_{2}$. A similar small drift of ca. $1.8 \mathrm{mV} \mathrm{h}^{-1}$ was observed when switching from oxygen-free $0.1 \mathrm{M} \mathrm{KCl}$ solution to air saturated (Figures S-4 S-6). The $\mathrm{O}_{2}$ and $\mathrm{CO}_{2}$ changes are more drastic than in most practical situations and are indicative of the worst case scenario.

\section{CONCLUSIONS}

We have used for the first time PPy doped with the hydrophobic PFOS $^{-}$anions as the ion-toelectron transducer in $\mathrm{K}^{+}$-SCISEs. The PPy transducers that are usually hydrophilic in their conducting form can thus be made hydrophobic with PFOS $^{-}$(WCA: 97 $\pm 5^{\circ}$ ). The $\mathrm{K}^{+}$-SCISEs 
have in the best case a very good $E^{0}$ reproducibility of only $\pm 0.7 \mathrm{mV}$, which is attributed to the combination of the pre-polarization of the PPy-PFOS solid contact and its excellent water barrier properties due to its high hydrophobicity. Mathematical modelling revealed that the water uptake of the PPy-PFOS film measured with the FTIR-ATR spectroscopy was best described with a model consisting of two diffusion coefficients, $D_{1}=9 \times 10^{-13} \mathrm{~cm}^{2} \mathrm{~s}^{-1}$ and $\mathrm{D}_{2}=2 \times 10^{-14} \mathrm{~cm}^{2} \mathrm{~s}^{-1}$ showing that the diffusion of water through the PPy-PFOS solid contact is very slow. PFOS $^{-}$was used in this work as a model compound, but because of its environmental risks, it is desirable to replace it with a more environmentally friendly hydrophobic compound.

\section{ACKNOWLEDGEMENTS}

N.H. and T.L. gratefully acknowledge the Academy of Finland for financial support (project number 260036, 130588 and 263656) and R.G. the Lendület program of the Hungarian Academy of Sciences (LP2013-63/13) and ERA-Chemistry (2014, 61133; OTKA NN117637). N.H. acknowledges also the research scholarships received from Åbo Akademi University and Johan Gadolin Process Chemistry Centre, and L.H. the Bolyai János Fellowship. Finally, we thank Dr. Pia Damlin at the University of Turku (Finland) for the assistance with the water contact angle measurements.

\section{ASSOCIATED CONTENT \\ Supporting Information}

Experimental descriptions of the electropolymerization of pyrrole on the ZnSe reflection element, potentiometric measurements including the determination of the selectivity 
coefficients, $\mathrm{O}_{2}, \mathrm{CO}_{2}$ and light sensitivity. Mathematical modeling of the water diffusion coefficients in the PPy-PFOS film and the assignments of its FTIR bands. SEM image of the PPy-PFOS film, potentiometric selectivity coefficients and potential traces of the $\mathrm{K}^{+}$-SCISEs in $10^{-10}-10^{-2} \mathrm{M} \mathrm{KCl}$ solutions.

\section{REFERENCES}

(1) Lindner, E.; Gyurcsányi, R. E.; Pretsch, E. In Applications of supramolecular chemistry for 21st century technology, Schneider, H.-J., Ed.; Taylor \& Francis: Boca Raton, 2012, pp xi, $441 \mathrm{p}$.

(2) Bakker, E.; Bühlmann, P.; Pretsch, E. Chem. Rev. 1997, 97, 3083-3132.

(3) Bobacka, J.; Ivaska, A.; Lewenstam, A. Chem. Rev. 2008, 108, 329-351.

(4) Oesch, U.; Ammann, D.; Simon, W. Clin. Chem. 1986, 32, 1448-1459.

(5) Jiawang, D.; Jiahong, L.; Xia, M.; Jun, G.; Wei, Q. Anal. Chem. 2014, 86, 9412-9416.

(6) Szücs, J.; Pretsch, E.; Gyurcsányi, R. E. Analyst 2009, 134, 1601-1607.

(7) Chumbimuni-Torres, K. Y.; Dai, Z.; Rubinova, N.; Xiang, Y.; Pretsch, E.; Wang, J.;

Bakker, E. J. Am. Chem. Soc. 2006, 128, 13676-13677. 
(8) Wang, X. W.; Yang, Y. G.; Li, L.; Sun, M. S.; Yin, H. G.; Qin, W. Anal. Chem. 2014, 86, 4416-4422.

(9) Gyurcsányi, R. E.; Vigassy, T.; Pretsch, E. Chem Commun 2003, 2560-2561.

(10) Szücs, J.; Gyurcsányi, R. E. Electroanalysis 2012, 24, 146-152.

(11) Hu, J.; Ho, K. T.; Zou, X. U.; Smyrl, W. H.; Stein, A.; Bühlmann, P. Anal. Chem. 2015, 87, 2981-2987.

(12) Lan, W.-J.; Zou, X. U.; Hamedi, M. M.; Hu, J.; Parolo, C.; Maxwell, E. J.; Bühlmann, P.; Whitesides, G. M. Anal. Chem. 2014, 86, 9548-9553.

(13) Gao, W.; Emaminejad, S.; Nyein, H. Y. Y.; Challa, S.; Chen, K.; Peck, A.; Fahad, H. M.; Ota, H.; Shiraki, H.; Kiriya, D.; Lien, D.-H.; Brooks, G. A.; Davis, R. W.; Javey, A. Nature 2016, 529, 509-514.

(14) Bandodkar, A. J.; Molinnus, D.; Mirza, O.; Guinovart, T.; Windmiller, J. R.; ValdesRamirez, G.; Andrade, F. J.; Schoening, M. J.; Wang, J. Biosens. Bioelectron. 2014, 54, 603609.

(15) Buck, R. P.; Lindner, E. Anal. Chem. 2001, 73, 88A-97A.

(16) Lindner, E.; Buck, R. P. Anal. Chem. 2000, 72, 336 A-345 A.

(17) Lindner, E.; Cosofret, V. V.; Ufer, S.; Buck, R. P.; Kusy, R. P.; Ash, R. B.; Nagle, H. T. J. Chem. Soc., Faraday Trans. 1993, 89, 361-367.

(18) Cadogan, A.; Gao, Z.; Lewenstam, A.; Ivaska, A.; Diamond, D. Anal. Chem. 1992, 64, 2496-2501.

(19) Michalska, A.; Hulanicki, A.; Lewenstam, A. Microchem. J. 1997, 57, 59-64.

(20) Lindner, E.; Gyurcsányi, R. E. J. Solid State Electrochem. 2009, 13, 51-68.

(21) Hu, J.; Stein, A.; Bühlmann, P. TrAC, Trends Anal. Chem. TRAC 2016, 76, 102-114.

(22) Nikolskii, B. P.; Materova, E. A. Ion Sel Electrode R 1985, 7, 3-39.

(23) Bobacka, J. Anal. Chem. 1999, 71, 4932-4937.

(24) Zwickl, T.; Schneider, B.; Lindner, E.; Sokalski, T.; Schaller, U.; Pretsch, E. Anal. Sci 1998, 14, 57-61.

(25) Li, Z.; Li, X. Z.; Rothmaier, M.; Harrison, D. J. Anal. Chem. 1996, 68, 1726-1734.

(26) Li, Z.; Li, X. Z.; Petrovic, S.; Harrison, D. J. Anal. Chem. 1996, 68, 1717-1725.

(27) Gyurcsányi, R. E.; Lindner, E. Cytometry Part A 2006, 69A, 792-804.

(28) Appiah-Kusi, C.; Kew, S. J.; Hall, E. Electroanalysis 2009, 21, 1992-2003. 
(29) Lindfors, T.; Sundfors, F.; Höfler, L.; Gyurcsányi, R. E. Electroanalysis 2009, 21, 19141922.

(30) Lindfors, T.; Sundfors, F.; Höfler, L.; Gyurcsányi, R. E. Electroanalysis 2011, 23, 21562163.

(31) Sundfors, F.; Lindfors, T.; Höfler, L.; Gyurcsányi, R. E. Anal. Chem. 2009, 81, 59255934.

(32) Fibbioli, M.; Bandyopadhyay, K.; Liu, S. G.; Echegoyen, L.; Enger, O.; Diederich, F.; Bühlmann, P.; Pretsch, E. Chem Commun 2000, 5, 339-340.

(33) Veder, J.-P.; De Marco, R.; Clarke, G.; Chester, R.; Nelson, A.; Prince, K.; Pretsch, E.; Bakker, E. Anal. Chem. 2008, 80, 6731-6740.

(34) Bobacka, J. Electroanalysis 2006, 18, 7-18.

(35) Michalska, A. Electroanalysis 2012, 24, 1253-1265.

(36) Szücs, J.; Lindfors, T.; Bobacka, J.; Gyurcsányi, R. E. Electroanalysis 2016, 28, 778-786.

(37) Crespo, G. A.; Macho, S.; Xavier Rius, F. Anal. Chem. 2008, 80, 1316-1322.

(38) Hu, J. B.; Zou, X. U.; Stein, A.; Bühlmann, P. Anal. Chem. 2014, 86, 7111-7118.

(39) Lai, C. Z.; Fierke, M. A.; Stein, A.; Bühlmann, P. Anal. Chem. 2007, 79, 4621-4626.

(40) Hernandez, R.; Riu, J.; Bobacka, J.; Valles, C.; Jimenez, P.; Benito, A. M.; Maser, W.

K.; Xavier Rius, F. J. Phys. Chem. C 2012, 116, 22570-22578.

(41) Sun, Q.; Li, W.; Su, B. J. Electroanal. Chem. 2015, 740, 21-27.

(42) Paczosa-Bator, B. Carbon 2015, 95, 879-887.

(43) Piek, M.; Piech, R.; Paczosa-Bator, B. Electrochim Acta 2016, 210, 407-414.

(44) Hauser, P. C.; Chiang, D. W. L.; Wright, G. A. Anal. Chim. Acta 1995, 302, 241-248.

(45) Ivanova, N. M.; Podeshvo, I. V.; Goikhman, M. Y.; Yakimanskii, A. V.; Mikhelson, K.

N. Sens. Actuators, B 2013, 186, 589-596.

(46) Zhou, M.; Gan, S.; Cai, B.; Li, F.; Ma, W.; Han, D.; Niu, L. Anal. Chem. 2012, 84, 34803483.

(47) Yin, T. J.; Pan, D. W.; Qin, W. Anal. Chem. 2014, 86, 11038-11044.

(48) Zeng, X. Z.; Yu, S. Y.; Yuan, Q.; Qin, W. Sens. Actuators, B 2016, 234, 80-83.

(49) Gyurcsányi, R. E.; Nyback, A. S.; Tóth, K.; Nagy, G.; Ivaska, A. Analyst 1998, 123, 1339-1344. 
(50) Sundfors, F.; Bereczki, R.; Bobacka, J.; Tóth, K.; Ivaska, A.; Gyurcsányi, R. E. Electroanalysis 2006, 18, 1372-1378.

(51) Gyurcsányi, R. E.; Rangisetty, N.; Clifton, S.; Pendley, B. D.; Lindner, E. Talanta 2004, 63, 89-99.

(52) Xu, L. B.; Chen, W.; Mulchandani, A.; Yan, Y. S. Angew. Chem. Int. Ed. 2005, 44, 6009-6012.

(53) Lindfors, T. J. Solid State Electrochem. 2009, 13, 77-89.

(54) Vanamo, U.; Bobacka, J. Anal. Chem. 2014, 86, 10540-10545.

(55) Zou, X. U.; Zhen, X. V.; Cheong, J. H.; Bühlmann, P. Anal. Chem. 2014, 86, 8687-8692.

(56) Chang, J. H.; Hunter, I. W. Macromol. Rapid Commun. 2011, 32, 718-723.

(57) Lindfors, T.; Höfler, L.; Jágerszki, G.; Gyurcsányi, R. E. Anal. Chem. 2011, 83, 49024908.

(58) Harrick, N. J. Internal reflection spectroscopy; Interscience Publishers: New York, 1967. (59) Sammon, C.; Mura, C.; Yarwood, J.; Everall, N.; Swart, R.; Hodge, D. J. Phys. Chem. B 1998, 102, 3402-3411.

(60) Sutandar, P.; Ahn, D. J.; Franses, E. I. Macromolecules 1994, 27, 7316-7328.

(61) Socrates, G. Infrared and Raman Characteristic Group Frequencies, Tables and Charts, p. 301, 3rd ed.; John Wiley \& Sons, Ltd: Chichester, 2001.

(62) Kim, D.; Lee, D.; Paik, W. K. Bull. Korean Chem. Soc. 1996, 17, 707-712.

(63) Zhong, C. J.; Doblhofer, K. Electrochim Acta 1990, 35, 1971-1976.

(64) Davidson, R. G.; Turner, T. G. Synth. Met. 1995, 72, 121-128.

(65) Socrates, G. Infrared and Raman Characteristic Group Frequencies, Tables and Charts, p. 182, 3rd ed.; John Wiley \& Sons, Ltd: Chichester, 2001.

(66) Kvarnström, C.; Ivaska, A.; Neugebauer, H. In Advanced Functional Molecules and Polymers, Vol. 2, Processing and Spectroscopy, pp. 139-169, Nalwa, H. S., Ed.; Gordon \& Breach Science Publishers, 2001.

(67) Neugebauer, H. Macromol. Symp. 1995, 94, 61-73.

(68) He, N.; Lindfors, T. Anal. Chem. 2013, 85, 1006-1012.

(69) Sundfors, F.; Höfler, L.; Gyurcsányi, R. E.; Lindfors, T. Electroanalysis 2011, 23, 17691772. 
(70) Socrates, G. Infrared and Raman Characteristic Group Frequencies, Tables and Charts, p. 221, 3rd ed.; John Wiley \& Sons, Ltd: Chichester, 2001.

(71) He, N.; Höfler, L.; Latonen, R.-M.; Lindfors, T. Sens. Actuators, B 2015, 207, 918-925.

(72) Bakker, E. J. Electrochem. Soc. 1996, 143, L83-L85.

(73) Jarvis, J. M.; Guzinski, M.; Pendley, B. D.; Lindner, E. J. Solid State Electrochem. 2016, 20, 3033-3041.

(74) He, N.; Gyurcsányi, R. E.; Lindfors, T. Analyst 2016, 141, 2990-2997.

(75) Sutter, J.; Pretsch, E. Electroanalysis 2006, 18, 19-25.

(76) Vazquez, M.; Danielsson, P.; Bobacka, J.; Lewenstam, A.; Ivaska, A. Sens. Actuators, B 2004, $97,182-189$.

\section{For TOC only}

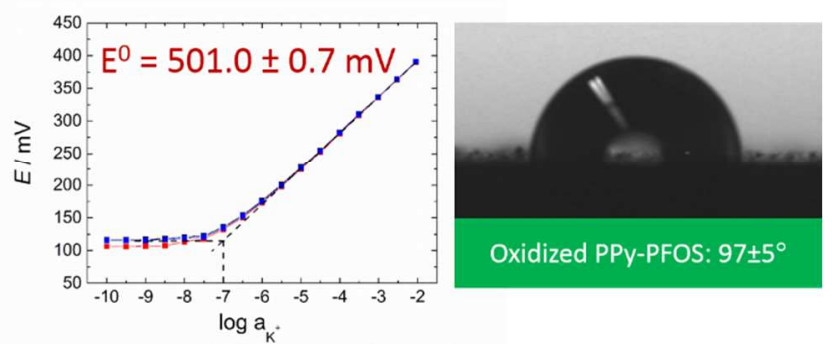

